\title{
Rede de conhecimento sobre a produção quilombola de alimentos no IFSP Campus \\ Registro: cultura e tradição alimentar
}

\author{
Knowledge network on quilombola food production in the IFSP Campus Registro: \\ culture and food tradition
}

\author{
lamara de Almeida Nepomuceno ${ }^{1}$ \\ Juliana Cesário Aragi 2
}

O Vale do Ribeira está entre as áreas de maior preservação da Mata Atlântica. Neste bioma habitam 88 comunidades quilombolas que praticam a agricultura de coivara itinerante. Segundo o Instituto Socioambiental (2017), o sistema agrícola tradicional quilombola (SAT) se define por saberes, técnicas aplicadas na agricultura de subsistência, na medicina e cultura material. Assim, o SAT norteia as relações e organizações de trabalho, os contextos sociais de plantio, colheita e consumo dos produtos dentro das comunidades produtores nesse sistema. Com programas como o Programa Nacional de Alimentação Escolar (PNAE) e o Programa de Aquisição de Alimentos (PAA) existem melhores condições de manutenção dos meios e modos de vida das comunidades quilombolas, garantindo maior autonomia e a permanência na terra. Nesta pesquisa, buscamos compreender em que medida os esforços realizados pelo IFSP sobre esses programas pode ajudar na ampliação do conhecimento dessas tradições no âmbito institucional. Este questionamento se deu com o desenvolvimento do projeto ligado à implantação, em 2018, de uma horta no Instituto Federal de Educação, Ciência e Tecnologia de São Paulo (IFSP), campus Registro, intitulado "Quilombos de lá, quilombos de cá: uma vivência na horta escolar". Analisamos fontes orais com base no método da história oral: documentos produzidos para o reconhecimento do SAT como Patrimônio Imaterial Brasileiro, o Dossiê SAT Quilombola do Vale do Ribeira (2017), bem como o Inventário Cultural de Quilombos do Vale do Ribeira (2013). Estes relatos são fontes documentais e, portanto, passíveis de interpretação, análise e crítica. Na abordagem teórica, trabalhamos conceitos de identidades, apresentadas por Anthony Kwame Appiah como complexas e múltiplas, elas surgem de uma história de respostas mutáveis às forças econômicas, políticas e culturais, quase sempre em oposição a outras identidades; bem como a memória discutida por Michael Pollak, que, construída socialmente, é formadora do sentimento de identidade, tanto individual como coletiva. Tomamos para estudo de caso o referido projeto de extensão desenvolvido com quilombolas de Sapatu, através de seus conhecimentos e da prática da agricultura tradicional dentro do campus; dois alunos quilombolas foram bolsistas. Como resultado, ocorreu aproximação dos alunos com a realidade quilombola e dos alunos quilombolas que estudam na instituição; valorizou-se o consumo de alimentos in natura, sem agrotóxicos; e estimularam-se parcerias nos processos de compras institucionais de alimentos: a banana fornecida pelo PNAE em 2019 para os alunos será de Sapatu.

Palavras-chave: povos tradicionais; quilombos; memória; agricultura; alimentação.

Keywords: traditional communities; quilombos; memory; agriculture; food.

1 Mestra em História Social na Universidade de São Paulo.

2 Graduada em Nutrição na Universidade de São Paulo. 